\title{
BIOMIMETIC REMINERALIZATION WITH NANO-HYDROXYAPATITE TREATMENT OF ENAMEL EROSION (AN IN VITRO STUDY)
}

\author{
Mohamed Wakwak*
}

\begin{abstract}
Objective: The objective of this study was to determine the effect of nano-hydroxyapatite and different bioactive remineralizing agent in the treatment of loss of enamel minerals. Material \&Methods: Initial enamel lesions were prepared in human enamel with an acid etching, then three remineralizing agents were applied on labial surface; nano-hydroxyapatite, casein phospho-peptide amorphous calcium phosphate and sodium fluoride, while artificial saliva was applied on control specimens. Surface microhardness measurements baseline were calculated, and before/after demineralization, surface roughness was seen using a digital 3D Profilometer. Results: Nano-hydroxyapatite group showed no significant difference mean hardness with CPP-ACP nanoparticle group while there is a significant difference between other remineralizing material. Nanohydroxyapatite was significantly greater than other material. Conclusion: Nano-hydroxyapatite has the potential to remineralize initial enamel lesions. Nano-hydroxyapatite and CPP-ACP are bioactive remineralizing agent that improve loss of enamel minerals. Nano-hydroxyapatite may be optimal for remineralization of early enamel caries.
\end{abstract}

KEYWORDS: Biomimetic Remineralization, Nano-Hydroxyapatite, Enamel Erosion.

\section{INTRODUCTION}

Dental caries is the most common oral disease ${ }^{(1)}$. Enamel erosion is the decomposition of inorganic particles and demineralization ${ }^{(2)}$. Enamel is both acellular and avascular and cannot heal itself by a cellular repair mechanism. The formation of incipient enamel caries is a reversible process where periods of progression alternates with periods of remineralization ${ }^{(3)}$. Remineralization become the predominant process, leading to apparent repair of the lesion ${ }^{(4)}$.

Fluoride was the most useful effective remineralizing agents in caries prevention ${ }^{(5)}$. Hydroxyapatite (HA) is one of the most biocompatible and bioactive materials and is widely applied nanosized particles ${ }^{(6)}$. Nano-hydroxyapatite has a similar morphology to crystal apatite of enamel and added to toothpastes, mouthwashes ${ }^{(7)}$. Therefore, the efficacy of prevention of enamel erosion depends on the actual precipitation of hydroxyapatite structure like enamel required for the remineralization process ${ }^{(8)}$.

Casein phospho-peptide amorphous calcium phosphate (CPP-ACP); ACP complexed with milk protein have a multifactorial anticariogenic effect and remineralization potential and are available as a topical nano-complex cream ${ }^{(9)}$. It promotes remineralization of the carious lesions by maintaining a supersaturated state of minerals; in addition to maintaining a high concentration of calcium and phosphate ions ${ }^{(10)}$. The aim of this study was to evaluate the remineralization effect

* Lecturer of Operative Dentistry, Faculty of Dental Medicine, Boys, Al Azhar University, Cairo

-Corresponding author: drwakwak2006@azhar.edu.eg

DOI: 10.21608 /ajdsm.2020.23266.1141 
of nano-hydroxyapatite in comparison to other remineralizing agents to improve enamel and stop the progression of carious disease.

\section{SUBJECTS AND METHODS}

Sixty sound non carious human anterior teeth extracted for pathologic reasons were collected from outpatient Surgery Clinic, Faculty of Dental Medicine, Al Azhar University. Teeth that were free of cracks and any developmental defects were washed and scaled to remove calculus and remnants of periodontal tissue and polished with fine pumice and soft rubber cups rotating at low speed under water coolant. Teeth were stored in distilled water at room temperature until use.

The labial surface of each sound tooth was then coated with acid resistant nail varnish leaving a window of $1 \mathrm{~mm} \times 1 \mathrm{~mm}$ wide ${ }^{(11)}$. Acid etching with $35 \%$ phosphoric acid (3M ESPE) for 1 minute was applied to create erosive enamel lesion of approximately 100-120 $\mu$ m deep among the selected teeth. After that teeth were subjected to sectioning longitudinally using microtome (Isomet 4000, Buehler, Lake Bluff, IL, USA). Teeth were randomly divided into four equal groups, with 15 in each group as follows: Group A, nanohydroxyapatite (Nanostreams NS0012): Group B, GC MI paste plus (CPP ACP) (GC International, Itabashi- $\mathrm{Ku}$, Tokyo, Japan.); Group C, Sodium Fluoride (Sultan Healthcare, USA); Group D, positive control artificial saliva (prepared at Department of Chemistry, Faculty of Science, AlAzhar University).

Surface treatments: The application of remineralizing agent on labial surfaces of specimens by disposable brush and scrubbing the surface with brushing motion for 20 seconds three times for group (A, B\&C). While group (D) specimens were immersed in artificial saliva for 3 minutes. All samples were stored in artificial saliva at $37^{\circ}$ in an incubator with $100 \%$ humidity at different storage times (one day, one week, and one month) and the artificial saliva changed daily.
Microhardness assessment: Surface microhardness of the specimens was determined (baseline, demineralized and after remineralization) using Digital Display Vickers Micro-hardness Tester (model HVS-50, Laizhou Huayin testing instrument Co. Ltd., China) with a Vickers diamond indenter and a 20X objective lens. A load of $200 \mathrm{~g}$ was applied to the surface of the specimens for 20 seconds. Three indentations, which were equally placed over a circle and not closer than $0.5 \mathrm{~mm}$ to the adjacent indentations, were made on the surface of each specimen. Micro-hardness was obtained using the following equation $\mathrm{HV}=1.854 \mathrm{P} / \mathrm{d} 2$ where, $\mathrm{HV}$ is Vickers hardness in $\mathrm{Kgf} / \mathrm{mm}^{2}$, $\mathrm{P}$ is the load in $\mathrm{Kgf}$ and $\mathrm{d}$ is the length of the diagonals in $\mathrm{mm}$.

Surface roughness assessment: Enamel surface roughness of each specimen was determined using non-contact profilometer. The optical methods tend to fulfill the need for quantitative characterization of surface topography without contact. Specimens were photographed using USB Digital microscope with a built-in camera connected with an IBM compatible personal computer using a fixed magnification of $90 \mathrm{X}$. The images were recorded with a resolution of $1280 \times 1024$ pixels per image. Digital microscope images were cropped to $350 \times 400$ pixels using Microsoft office picture manager to specify/standardize area of roughness measurement. The cropped images were analyzed using WSxM software. Within the WSxM software, all limits, sizes, frames and measured parameters are expressed in pixels. Therefore, system calibration was done to convert the pixels into absolute realworld units. Calibration was made by comparing an object of known size (a ruler in this study) with scale generated by the software. Subsequently, a 3D image of the surface profile of the specimens was created. 3D images were collected for each specimen, both in the central area and in the sides at area of $10 \mu \mathrm{m} \times 10 \mu \mathrm{m}$. WSxM software was used to calculate average roughness expressed in $\mu \mathrm{m}$ which can be assumed as a reliable indices of surface roughness. 
The data were collected, tabulated and statistically analyzed by Kolmogorov-Smirnov and Shapiro-Wilk tests and showed parametric (normal) distribution. ANOVA test was used followed by Tukey's post-hoc were used to compare between different variables. The significance level was set at $\mathrm{P} \leq 0.05$. Statistical analysis was performed with IBM ${ }^{\circledR}$ SPSS $®$ Statistics Version 20 for Windows.

\section{RESULTS}

The result table (1) of nano-hydroxyapatite group; baseline showed the highest significant mean Hardness followed by remineralized and demineralized with no significant difference between each other. While in CPP-ACP nanoparticle group; baseline showed the highest mean Hardness followed by remineralized and demineralized with no significant difference between each other.

However, (figure 1) sodium fluoride nanoparticle group; baseline showed the highest significant mean Hardness followed by remineralized and demineralized with no significant difference between each other. Similarly, artificial saliva group; baseline showed the highest mean hardness followed by demineralized and remineralized with no significant difference between each other.

TABLE (1) Effect of microhardness on nanoparticles

\begin{tabular}{|l|l|l|l|l|}
\hline & \multicolumn{3}{|c|}{ Microhardness Mean \pm SD } & \\
\hline Type of Nanoparticles & Baseline & Demineralized & Remineralized & P-value \\
\hline NanoHydroxyapatite (n HA) & $312.00^{\mathrm{a}} \pm 8.98$ & $275.00^{\mathrm{b}} \pm 13.49$ & $286.68^{\mathrm{b}} \pm 11.29$ & $0.004^{*}$ \\
\hline (CPP-ACP) & $293.67 \pm 29.16$ & $235.00 \pm 22.91$ & $271.07 \pm 45.09$ & $0.180 \mathrm{~ns}$ \\
\hline Sodium fluoride NaF & $292.67^{\mathrm{a}} \pm 25.11$ & $231.00^{\mathrm{b}} \pm 20.30$ & $252.33^{\mathrm{b}} \pm 17.79$ & $0.003^{*}$ \\
\hline Artificial saliva AS & $295.67 \pm 21.39$ & $243.67 \pm 37.85$ & $218.00 \pm 35.76$ & $0.065 \mathrm{~ns}$ \\
\hline
\end{tabular}

CPP-ACP; Casein phospho-peptide amorphous calcium phosphate

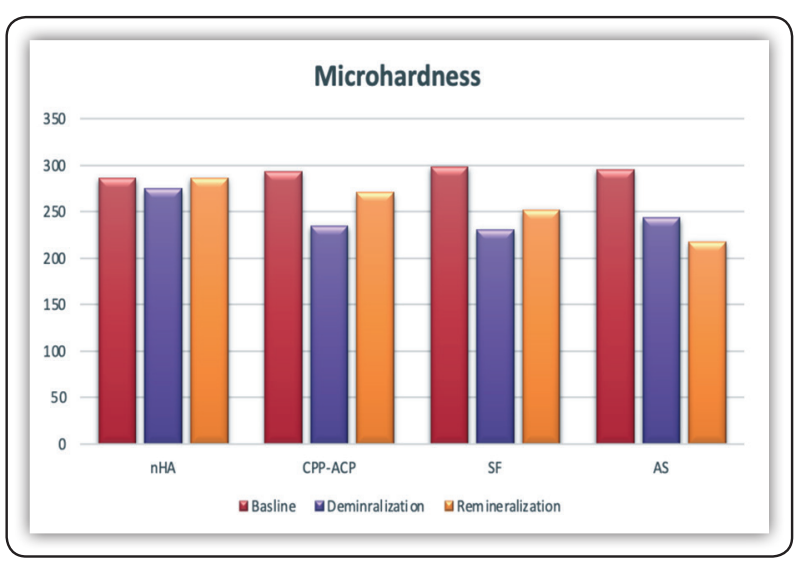

FIG (1) Bar chart showing comparison of different types of nanoparticles groups on enamel microhardness.
The effect of storage for one day, one week, and one month on nano-hydroxyapatite group as seen in (table 2), showing baseline enamel microhardness mean values with a statistical insignificant difference between sodium fluoride nanoparticles and artificial saliva. While CPP-ACP showing no statistical insignificant difference. However, sodium fluoride and artificial saliva microhardness mean values revealed a statistical insignificant difference. 
TABLE (2) Comparison of different storage time of nanoparticles groups on enamel microhardness.

\begin{tabular}{|c|c|c|c|c|c|}
\hline \multirow{2}{*}{\multicolumn{2}{|c|}{ Type of Nanoparticles }} & \multicolumn{3}{|c|}{ Microhardness Mean \pm SD } & \multirow{3}{*}{\begin{tabular}{|l|} 
p-value \\
$0.651 \mathrm{~ns}$
\end{tabular}} \\
\hline & & \multirow{2}{*}{$\begin{array}{r}\text { Baseline } \\
293.67 \pm 29.16\end{array}$} & \multirow{2}{*}{\begin{tabular}{|r|} 
Demineralized \\
$235.00 \pm 22.91$
\end{tabular}} & \multirow{2}{*}{$\begin{array}{r}\text { Remineralized } \\
271.07 \pm 45.09\end{array}$} & \\
\hline \multirow{3}{*}{$\begin{array}{l}\text { Nano Hydroxyapatite } \\
\text { (n } H A)\end{array}$} & 1 day & & & & \\
\hline & 1 week & $281.67 \pm 29.16$ & $249.00 \pm 22.91$ & $271.07 \pm 45.09$ & $0.210 \mathrm{~ns}$ \\
\hline & 1 month & $267.67 \pm 25.11$ & $293.00 \pm 20.30$ & $265.33 \pm 17.79$ & $0.008 \mathrm{~ns}$ \\
\hline \multirow{3}{*}{ (CPP-ACP) } & 1 day & $310.67 \pm 12.10$ & $247.33 \pm 15.04$ & $272.00 \pm 12.49$ & $0.935 \mathrm{~ns}$ \\
\hline & 1 week & $266.67 \pm 29.16$ & $288.00 \pm 22.91$ & $271.07 \pm 45.09$ & $0.160 \mathrm{~ns}$ \\
\hline & 1 month & $291.67 \pm 25.11$ & $261.00 \pm 20.30$ & $274.33 \pm 17.79$ & $0.006 \mathrm{~ns}$ \\
\hline \multirow{3}{*}{ Sodium flouride $\mathrm{NaF}$} & 1 day & $283.67 \pm 34.21$ & $232.33 \pm 46.80$ & $269.67 \pm 29.50$ & $0.202 \mathrm{~ns}$ \\
\hline & 1 week & $293.67 \pm 29.16$ & $235.00 \pm 22.91$ & $271.07 \pm 45.09$ & $0.080 \mathrm{~ns}$ \\
\hline & 1 month & $292.67 \pm 25.11$ & $231.00 \pm 20.30$ & $252.42 \pm 17.79$ & $0.03 \mathrm{~ns}$ \\
\hline \multirow{3}{*}{ Artificial saliva $A S$} & 1 day & $295.67 \pm 21.39$ & $243.67 \pm 37.85$ & $218.98 \pm 35.76$ & $0.023 \mathrm{~ns}$ \\
\hline & 1 week & $286.67 \pm 29.16$ & $290.00 \pm 22.91$ & $244.67 \pm 45.09$ & $0.180 \mathrm{~ns}$ \\
\hline & 1 month & $254.67 \pm 25.11$ & $249.00 \pm 20.30$ & $273.56 \pm 17.79$ & $0.008 \mathrm{~ns}$ \\
\hline
\end{tabular}

CPP-ACP; Casein phospho-peptide amorphous calcium phosphate

\section{Profilometer photo scanning results figure(2,3):}

The surface topography of remineralization with nano hydroxyapatite is resembling the surface topography of sound enamel. Also, the remineralization with Casein phosphopeptide-Amourphous Calcium Phosphate revealed a surface topography effect of remineralization.

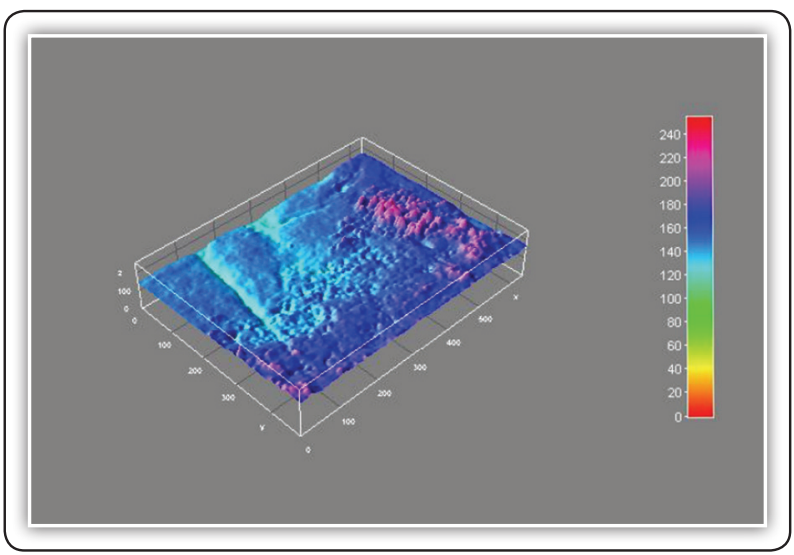

FIG (2) Optical scan of the sample after nano hydroxyappetite application.



FIG (3) Optical scan of the sample After Casein phosphopeptide Amourphous Calcium Phosphate application. 


\section{DISCUSSION}

In the current study, nano-hydroxyapatite was directly selected as a biomimetic remineralizing agent as its deposition of calcium / phosphate minerals in enamel resembling the hydroxyapatite, however, the crystalline deposition of minerals mimic the natural one and due to filling the micropores on demineralized enamel ${ }^{(8)}$. Nano-hydroxyapatite particles were regularly deposited on the demineralized enamel surface. Non-cavitated lesions as well as carious extending up to dentino-enamel junction can be arrested if the cariogenic challenges of the micro-environment are sufficiently controlled or/and if therapeutic agents are applied for tissue healing. Sodium fluoride, CPP-ACP nanocomplexes and Nano-hydroxyapatite particles demonstrated remineralizing capacity ${ }^{(12)}$.

These results confirmed the ability of nanohydroxyapatite to aid in remineralizing enamel. The higher effect of n-HA has been attributed to elevation of calcium concentrations causing the remineralization of early caries lesions ${ }^{(13)}$. Large amounts of calcium and phosphate ions in CPP-ACP nanocomplexes promote the enamel like crystal ${ }^{(14)}$.

Optical Profilometer determine the thickness of enamel structure and progression of remineralization indirectly by special software or by scanning the tomography, also, measure the hardness ${ }^{(15)}$.

Nano-HA precipitation and deposition of $\mathrm{Ca}^{2+}$ and $\mathrm{PO}_{4}$ accelerate the remineralization effect due to surface morphological structure $\mathrm{Wu}$ et al (16), also, demonstrated that surface hardness of the demineralized enamel increased with nanoHA. It was clear that remineralization continued over an extended period. However, the rate of remineralization in all treatments of mineral deposition in erosive lesions also supported the data of the current study.

Furthermore, the higher microhardness value of nHA group can be explained by the presence of $\mathrm{Ca} / \mathrm{PO}_{4}$ that induce precipitation of apatite by the formation of sub-surface high mineral content ${ }^{(17)}$. Another explanation might be attributed to porous, partially demineralized and wide surface area ${ }^{(18)}$.

The results are in agreement with Surmeneva et $\mathrm{al}^{(19)}$, they found that nano-HA promote preferential remineralization of the outer layer of enamel caries lesion and full remineralization does not occur. This indicates that nano-hydroxyapatite reveal a completely cure in remineralization of early enamel lesions ${ }^{(20)}$.

Calcium and phosphate are essential components in the presence of CPP, these minerals remain soluble that precipitate and maintain high concentrations of $\mathrm{ca} / \mathrm{p}$ ions on enamel surfaces, thus promoting remineralization ${ }^{(21)}$. CPP-ACP remineralizing potential that stabilize nanoclusters of amorphous calcium phosphate (ACP) with increase in minerals ratio. This is consistent with a previous in situ remineralization study which showed that the CPP-ACP containing gums were able to remineralize enamel subsurface lesions ${ }^{(22)}$.

ACP buffers the free $\mathrm{Ca} / \mathrm{P}$ ion to maintain a state of super-saturation on enamel surface, so promoting remineralization (13). Moreover, it has been suggested that the mechanism of this action is related to the phospho-peptide casein and calcium phosphate components ${ }^{(23)}$.

On the other hand, when sodium fluoride reacts produce fluorapatite and sodium hydroxide, the fluorapatites is more acid resistant than hydroxyapatite and sodium hydroxide increased the $\mathrm{pH}$ of the treatment media ${ }^{(24)}$. Despite, release of fluoride over a prolonged period, remineralization enhanced in the $\mathrm{NaF}$ groups. Moreover, the remineralizing agents have pointed to the resistance to erosion of tooth surfaces similarly by artificial saliva ${ }^{(25)}$. Demineralization caused by acidic beverages may have the tendency to decrease with the exposure to saliva including a remineralizing solution in the mouth. 


\section{CONCLUSIONS}

Within the limitations of this in vitro study, the following conclusions can be drawn:

1. Nano-hydroxyapatite has the potential to remineralize initial enamel lesions.

2. Nano-hydroxyapatite and CPP-ACP are bioactive remineralizing agent that improve loss of enamel minerals.

3. Nano-hydroxyapatite may be optimal for biomimetic remineralization of enamel erosion.

\section{REFERENCES}

1. Pintanon P, Sattabanasuk V, Banomyong D. Effectiveness of caries infiltration and CPP-ACP containing paste on color change and surface hardness of artificial white Spot enamel lesions. J Dent AssocThai. 2016; 66:133- 47.

2. Paris S, Schwendicke F, Seddig S, Muller WD, Dorfer C, Meyer- Lueckel H. Micro-hardness and mineral loss of enamel lesions after infiltration with various resins: Influence of infiltrant composition and application frequency in vitro. J Dent. 2013; 41: 543- 8 .

3. Zamorano Pino X, Valenzuela A, Vial P, Vidal M. Microhardness of artificial white-spot lesions infiltrated with low viscosity resins before and after thermocycling. Av Odontoestomatol. 2015; 31:371-8.

4. Tostes M, Santos E, Camargo S. Effect of resin infiltration on the nanomechanical properties of demineralized bovine enamel. Indian J Dent. 2014; 5: 116-22.

5. Arnold W, Meyer A, Naumove E. Surface roughness of initial enamel caries lesions in human teeth after resin infiltration. Open Dent J. 2016; 10: 505- 15.

6. Elhiny O, Salem G. Will resin infiltration with ICON prevent enamel demineralization around orthodontic bracket? Int. J. Adv. Res. 2016; 4: 1661- 7

7. El Zankalouny, El Fattah W, El-Shabrawy S. Penetration depth and enamel micro hardness of resin infiltrant and traditional technique of artificial enamel lesion. Alex. Dent.J. 2016; 41:20-5.

8. Taleb H, Rashed M, El-bardissy A, Bin Alshaibah W. Comparison of casein phosphopeptide-amorphous calcium phosphate and fluoride gel in remineralization of demineralized human enamel surfaces. Indian J Dent, 2012; 3: 53-7.
9. Amaechi BT, Lemke KC, Saha S, Gelfond J. Clinical efficacy in relieving dentin hypersensitivity of nanohydroxyapatite-containingcream: A randomized controlled trial. Open Dent J 2018;12:572-585

10. Pishehvar L, Mazaheri R, Mirzakhani M, Mohammad H, Nazari M, Ranjbaran F. Comparison study on casein phosphopeptide - amorphous calcium phosphate paste and fluoride gel on remineralization of demineralized enamel lesions. J Dent Sci. 2015; 33: 80 -7.

11. Itthagarun A, King NM, Cheung YM. The effect of nano-hydroxyapatite toothpaste on artificial enamel carious lesion progression: An in vitro $\mathrm{pH}$-cycling study. Hong Kong Dent J 2010;7:61-6.

12. Vajrabhaya LO, Korsuwannawong S, Harnirattisai C, Teinchai C. Changes in the permeability and morphology of dentine surfaces after brushing with a Thai herbal toothpaste: a preliminary study. Eur J Dent 2016;10:239-44.

13. Ishihata H, Kanehira M, Finger WJ, Shimauchi H, Komatsu M. Effects of applying glutaraldehyde-containing desensitizer formulations on reducing dentin permeability. $\mathrm{J}$ Dent Sci 2012;7:105-10.

14. Sun J, Chen C, Pan H, Chen Y, Mao C, Wang W, et al. Biomimetic promotion of dentin remineralization using 1glutamic acid: inspiration from biomineralization proteins . J Mater Chem B 2014;2:4544.

15. Wang Z, Xu Z, Zhao W, Sahai N. A potential mechanism for amino acid-controlled crystal growth of hydroxyapatite. J Mater Chem B 2015;3:9157-67.

16. Wu X, Zhao X, Li Y, Yang T, Yan X, Wang K. In situ synthesis carbonated hydroxyapatite layers on enamel slices with acidic amino acids by a novel two-step method. Mater Sci Eng C Mater Biol Appl 2015;54:150-7.

17. Dai Z, Liu M, Ma Y, et al. Effects of fluoride and calcium phosphate materials on remineralization of mild and severe white spot lesions. BioMed Res Int 2019;2019:1271523

18. Carrouel F, Viennot S, Ottolenghi L, Gaillard C, Bourgeois D. Nanoparticles as anti-microbial, anti-inflammatory, and remineralizing agents in oral care cosmetics: a review of the current situation. Nanomaterials 2020;10(1):1-32.

19. Surmeneva MA, Mukhametkaliyev TM, Tyurin AI. Effect of silicate doping on the structure and mechanical properties of thin nanostructured RF magnetron sputter-deposited hydroxyapatite films. Surf Coat Tech 2015;275:176-184.

20. Onwubu SC, Mdluli PS, Singh S, Bharuth V, Makgobole MU. Evaluation of the occluding characteristics of nanosized eggshell/ titanium dioxide with or without saliva. Eur J Dent 2019;13(4):547-555. 
21. Peumans M, Politano G, Van Meerbeek B. Treatment of noncarious cervical lesions: when, why, and how. Int J Esthet Dent 2020;15(1):16-42.

22. Tian L, Peng C, Shi Y, et al. Effect of mesoporous silica nanoparticles on dentinal tubule occlusion: an in vitro study using SEM and image analysis. Dent Mater J 2014;33(1):125-132.

23. Elgamily H, Safwat E, Soliman Z, Salama H, El-Sayed H, Anwar M. Antibacterial and remineralization efficacy of casein phosphopeptide, glycomacropeptide nanocomplex, and probiotics in experimental toothpastes: an in vitro comparative study. Eur J Dent 2019;13(3):391-39.

24. Tomaz PLS, Sousa LA, Aguiar KF, et al. Effects of 1450-ppm fluoride containing toothpastes associated with boosters on the enamel remineralization and surface roughness after cariogenic challenge. Eur J Dent 2020;14(1):161-170.

25. Vilhena FV, Polassi MR, Paloco EAC, Alonso RC, Guiraldo RD, D'Alpino PH. Effectiveness of toothpaste containing REFIX technology against dentin hypersensitivity: a randomized clinical study. J Contemp Dent Pract 2020;21(6):609-614. 